\title{
TECNOLOGIAS EDUCACIONAIS EM REDE COMO MEDIADORAS DO ENSINO-APRENDIZAGEM DA AGROECOLOGIA: PRODUÇÃO E USO DO AUDIOVISUAL NAS CIÊNCIAS AGRÁRIAS
}

\author{
Rogério Oliveira Pinheiro ${ }^{1}$ \\ Gisele Martins Guimarães ${ }^{2}$
}

\begin{abstract}
RESUMO
O presente trabalho apresenta o uso pedagógico das Tecnologias Educacionais em Rede (TER), mais especificamente o vídeo, como mediador do ensinoaprendizagem das Ciências Agroecológicas. São abordados resultados de uma pesquisa realizada por meio do uso de questionários, com 30 alunos dos cursos das Ciências Agrárias (Agronomia, Medicina Veterinária, Zootecnia e Pós-Graduação em Extensão Rural) da Universidade Federal de Santa Maria-Rs/Brasil identificando entre estes, percepções acerca da funcionalidade do audiovisual no ensinoaprendizagem. As percepções apontam para a aceitação do audiovisual como importante mediador do ensino elencando este como ferramenta capaz de dar visibilidade às experiências locais e regionais possibilitando, mesmo que virtualmente, trocas de saberes e vivências, pois os sentidos permanecem estimulados por meio de som, depoimentos, imagens em movimentos e emoções partilhadas. Os resultados ainda apontam para a necessidade de revisão das práticas docentes e das bases epistemológicas onde se ancoram as Ciências Agrárias, uma vez que a contemporaneidade requer novos posicionamentos para a formação de profissionais capazes de contribuir com o Desenvolvimento Sustentável, este alicerçado na equidade social, saberes tradicionais, equilíbrio dos ecossistemas e autonomia dos sujeitos.
\end{abstract}

Palavras-chave: agroeocologia, sustentabilidade, tecnologias educacionais.

\section{EDUCATIONAL TECHNOLOGIES IN NETWORK AS EDUCATIONAL MEDIATORS LEARNING OF AGROECOLOGY: PRODUCTION AND USE OF AUDIOVISUAL IN AGRICULTURAL SCIENCES}

\begin{abstract}
The present work presents the pedagogical use of Network Educational Technologies (TER), more specifically video, as mediator of the teaching-learning of Agroecological Sciences. The results of a research carried out using questionnaires, with 30 students of Agrarian Sciences (Agronomy, Veterinary Medicine, Zootechnics

\footnotetext{
${ }^{1}$ Graduado em Zootecnia (UFSM). Mestrado em Tecnologias Educacionais em Rede (UFSM). Aluno do Programa de Graduação Especial - PEG (UFSM). E-mail: maninhopinheiro@yahoo.com.br

${ }^{2}$ Graduada em Zootecnia (UFSM). Mestrado em Extensão Rural (UFSM). Doutorado em Desenvolvimento Rural (UFRGS). Professora Adjunta do Departamento de Educação Agrícola e Extensão Rural e Programa de Pós-Graduação em Extensão Rural (UFSM). E-mail: giseleguima@yahoo.com.br
} 
and Post Graduation in Rural Extension) of the Federal University of Santa MariaRs/Brazil, perceptions about the functionality of audiovisual in teaching-learning. The perceptions point to the acceptance of the audiovisual as an important mediator of teaching, as it is a tool capable of giving visibility to local and regional experiences, allowing, even if virtually, exchanges of knowledge and experiences, since the senses remain stimulated through sound, images in shared movements and emotions. The results still point to the need to revise teaching practices and the epistemological bases where the Agricultural Sciences are anchored, since contemporaneity requires new positions for the formation of professionals capable of contributing to Sustainable Development, based on social equity, traditional knowledge, ecosystem equilibrium and the autonomy of subjects.

Keywords: agroecology, educational technologies, sustainability.

\section{INTRODUÇÃO}

Em um mundo sob constantes transformações socioeconômicas e culturais, a educação precisa ir além da assimilação certificada de saberes e simples transferência de conhecimento. É preciso interagir com a comunidade a partir de processos emancipatórios e transformadores, nos quais os sujeitos envolvidos conhecem a realidade e, sobretudo a interpretam e transformam (FREIRE, 1992).

Tais pressupostos devem ser observados nos mais diferentes espaços educacionais, desde a escola até as universidades, cada vez mais impregnadas de uma "educação bancária" onde o educador é detentor do conhecimento, e "deposita" certa quantidade de conhecimentos nos educandos, que por sua vez, absorvem passivamente (FREIRE, 1987).

Como contraponto a esta práxis pedagógica, o presente trabalho discute as Tecnologias Educacionais em Rede (TER) como objeto educacional capaz de promover mediação de conhecimentos, buscando incorporar elementos de criatividade, autonomia e valorização do cotidiano nos processos de ensinoaprendizagem. As TER oferecem possibilidades de inovação pedagógica por meio de elementos facilitadores do diálogo, como os mecanismos de audiovisual a serem utilizados nos espaços de troca e formação do conhecimento sejam por meio de reflexões promovidas pelas informações oferecidas, ou ressignificações geradas pelos sujeitos que a recebem.

O Vídeo é um material intelectual que processa a reflexão, gera e inventa ideias. Machado (2005) acena para este como um sistema híbrido que opera com diversos códigos significantes, com elementos do cinema, do teatro, da literatura, do rádio e também da computação gráfica mostrando-se rico na medida em que se mostra aberto a criações e recriações de sentidos.

Possui a capacidade de potencializar conhecimentos populares e dinâmicos socioculturais estabelecidos entre os sujeitos, estas construídas a partir de significados intrínsecos a determinados grupos sociais como, por exemplo, saberesfazer estabelecidos a partir de conhecimentos intergeracionais ou ainda de agroecossistemas específicos, que quando sistematizados em sua abordagem educativa podem contribuir para sensibilização dos sujeitos a partir de suas culturas.

É neste contexto, de construção de objetos educacionais digitais como mediadores de saberes populares e científicos, que o presente artigo apresenta 0 potencial educativo do vídeo como instrumento para promoção e visibilidade da Agroecologia e educação para a sustentabilidade. Pretende-se assim contribuir, a partir de reflexões sobre o uso das TER, com os processos de ensino-aprendizagem 
nas Ciências Agrárias, onde as experiências e o cotidiano dos sujeitos expressam o conhecimento e vivência como grande fonte de ensinamento.

\section{O VÍDEO COMO TECNOLOGIA EDUCACIONAL EM REDE (TER)}

A sociedade informacional, assim denominada por Castells (1999), tem a informação como matéria-prima e passa por contínuas mudanças impulsionadas pelo desenvolvimento tecnológico e pelo uso que se faz da tecnologia, o que inclui a educação. Esta precisa estar pautada pela realidade como fonte inspiradora e problematizadora, na formação de cidadãos capazes de reconhecer criticamente e transformar a realidade onde vivem.

E é neste domínio que emergem as discussões sobre o papel e potencial transformador das Tecnologias Educacionais em Rede (TER) compreendidas como um modo sistemático de conceber, aplicar e avaliar o conjunto de processos do ensino-aprendizagem, levando em conta os recursos humanos e os tecnológicos, bem como as interações entre eles, como forma de obter uma educação mais efetiva (KENSKI, 2003).

As TER podem contribuir nas dinâmicas de ensino-aprendizagem quando utilizadas como meio de construção de novas possibilidades e mesmo como instrumento de motivação, criatividade e mediação social, isto porque tem a capacidade de promover interação entre os sujeitos e expandir suas possibilidades de construção do conhecimento (CASTELLS, 1999).

É importante ainda salientar o papel atribuído as TER, no sentido de prover acesso à informação e educação, indistintamente, a qualquer hora e em qualquer lugar. Nesta ótica, verifica-se que a inserção das Tecnologias da Informação e Comunicação (TIC) pelos agentes educadores através da inclusão do computador e outras mídias no ambiente de aprendizagem, oferecem acessos a diversas possibilidades de interação, mediação e manifestação de sentidos, propiciados pelos recursos disponíveis e as informações (ANDRADE; SANTOS, 2015).

A gama de possibilidades produzidas pelas TER surpreende-nos pelas múltiplas funções e capacidades que trazem incorporadas e que lhes permitem estar em um lugar de destaque e importância em todos os setores da sociedade.

No entanto, mesmo frente a uma expansão das tecnologias no âmbito da vida social, percebe-se que o ambiente escolar/acadêmico é onde mais lentamente as tecnologias adentram, ficando ainda mais evidente quando analisadas as práticas pedagógicas dos educadores (nas escolas e Universidades) evidenciando assim uma carência na preparação dos profissionais para o uso pedagógico das TER como um recurso colaborativo e cooperativo de aprendizagem seja pela possibilidade de diálogo ou mesmo a participação de todos os envolvidos.

Lévy (2000) acrescenta que a qualidade do processo de apropriação é mais importante do que as particularidades sistêmicas das ferramentas trazendo para a reflexão as formas de incorporação das tecnologias no cotidiano dos agentes educadores em suas práxis de ensino aprendizagem.

Desta forma, o compartilhamento e diálogo na construção do saber ocorrem por meio de um processo colaborativo que pode promover diversas formas e mecanismos de apropriação do conhecimento (FREIRE, 1992). Esse processo é denominado por Lévy de inteligência coletiva. Esta compreendida como uma reunião ou sinergia dos saberes, das imaginações, das energias espirituais de um grupo humano constituído como comunidade virtual (LÉVY, 2003).

Kenski (2003), por sua vez, aponta que um dos grandes desafios para ação da escola na atualidade é viabilizar-se como espaço crítico em relação ao uso e à apropriação das tecnologias de comunicação e informação (TIC). 
Vale ressaltar que mudaram os tempos e as necessidades, e por isto o uso das TIC no contexto escolar, necessita de preparação e participação tanto por parte do professor quanto do aluno, considerando que em muitas situações o uso das TIC é imposto sem reflexões.

Neste sentido Castells (2003) expõe em sua obra "A galáxia da Internet" que apesar da difusão, a lógica, a linguagem e os limites das TIC, como por exemplo, a Internet, não são bem compreendidas para além da esfera de disciplinas tecnológicas trazendo à tona a necessidade de diálogos para seu uso pedagógico.

O diálogo é uma das principais necessidades dos seres humanos, essencial à sobrevivência, assim este deve ser o ponto central do ensino, no qual educadores e educandos são ativos e igualmente importantes no processo.

Buscando-se incorporar elementos de comunicação, criatividade, autonomia e valorização do cotidiano nos processos de ensino-aprendizagem, as TER oferecem possibilidades de inovação pedagógica por meio de elementos facilitadores do diálogo, como os mecanismos de audiovisual a serem utilizados nos espaços de troca e formação do conhecimento sejam por meio de reflexões promovidas pelas informações oferecidas (em vídeos, por exemplo) ou ressignificações geradas pelos sujeitos que a recebem. Isto porque as TIC na educação podem possibilitar novas formas de sociabilidades promovendo interação e interatividade entre os agentes educadores, de proporcionar a afirmação de identidades e ainda espaços de construção de saberes e práticas, de forma conjunta entre educadores e educandos e, o mais significativo, a partir da realidade que os cercam.

Assim para que o processo de ensino-aprendizagem seja amplamente favorecido é necessário que as práticas pedagógicas favoreçam a integração de vários sentidos como a imaginação, intuição, colaboração e relações emocionais, uma vez que os aspectos estéticos, tais como a fotografia, o filme, a música, a dança, o teatro, a literatura e as artes plásticas agregam uma sofisticação à relação ensino-aprendizagem, visto que proporcionam a vivência, interação e interatividade, conectando sentidos, sentimentos e razão (MORAES; TORRES, 2004).

Buscando esclarecer as contribuições das práticas de interação e interatividade para construção do conhecimento Belloni (1999) elucida a diferença entre estas, considerando que a interação é uma ação recíproca entre dois ou mais sujeitos onde ocorre intersubjetividade, isto é, encontro de indivíduos, que pode ser direta ou indireta (mediatizada). Já a interatividade significa a potencialidade técnica oferecida por determinado meio (CD-ROMs de consulta, vídeos, hipertextos em geral, etc.) ou a atividade humana, do usuário, de agir sobre a máquina, e de receber, em troca, uma "retroação" da máquina sobre ele. Por esta razão deve-se estar atento para o fato de que o ensino-aprendizagem de qualidade deve proporcionar ampla possibilidade de interação entre os sujeitos, caso contrário passa a ser mera "educação bancária", como simples repositórios de conteúdo.

Este fato é corroborado na afirmativa de Moran (2000), de que aprendemos melhor quando vivenciamos, experimentamos, sentimos, relacionamos, estabelecemos laços entre o que estava disperso, dando-lhe significado, e encontrando um novo sentido. Desta forma podemos atribuir aspectos importantes para a promoção da interatividade como fonte de conhecimento e educação, aspectos estes que extrapolam a linguagem escrita, o que inclui sons, imagens, formas e sentimentos.

Por outro lado, Castells (2000), considera que a integração potencial de textos, imagens e sons no mesmo sistema, ao interagir a partir de pontos múltiplos em uma rede global, em condições de acesso aberto, pode mudar de forma 
fundamental o caráter da comunicação, em seu sentido educacional e não apenas informativo, contribuindo assim para as transformações culturais.

Dentro dos propósitos de Castells (1999) considerando a importância da relação integrada de elementos comunicadores, como imagem e som, para a construção e ou fortalecimento de saberes culturais, emerge a importância dos audiovisuais como instrumentos de mediação de conhecimentos.

Em uma produção midiática audiovisual é possível construir representações coletivas de grupos sociais, suas histórias, identidades e anseios. Por isso, o vídeo constitui importante dispositivo pedagógico pela sua capacidade de dar visibilidade ao cotidiano, com seus conflitos e potencialidades construindo assim identidades coletivas.

Como aponta Pires (2010) os elementos da linguagem verbal e da linguagem visual podem hoje coexistir num mesmo espaço. $O$ autor ainda pontua que "o vídeo é ao mesmo tempo objeto e processo, público e privado, pintura e televisão, sem ser um nem outro, ou sendo ambos, com um senso constante do ensaio, da pesquisa, da experimentação, da inovação" (PIRES, 2010, p. 286).

Por isso os modos de criação videográfica podem relativizar o modelo narrativo, desenvolvendo uma linguagem, ou estética particular, que põem em jogo questões diferentes das expostas pela linguagem escrita, desta forma o vídeo é o material formal e intelectual no qual se processa a reflexão ou ainda, que gera, que inventa, que dá corpo e materialidade as ideias (DUBOIS, 2004).

Assim, no contexto deste trabalho, relacionando dinâmicas de ensinoaprendizagem e a importância das Tecnologias Educacionais em Rede como facilitadores de diálogo entre os sujeitos, realiza-se uma reflexão acerca das potencialidades do uso de recursos audiovisuais como instrumento didático nas práticas pedagógicas dos professores de Ciências Agrárias, no processo de ensinoaprendizagem da Agroecologia, reconhecendo a importância desta para a produção sustentável de alimentos como um dos desafios a serem trilhados pela educação superior rumo a sustentabilidade.

\section{A AGROECOLOGIA E A EDUCAÇÃO PARA A SUSTENTABILIDADE}

O Paradigma da sustentabilidade idealizado a partir do Relatório Brundtland de 1987 (intitulado "Nosso futuro Comum") preconiza a necessidade da equalização do crescimento populacional e econômico com a disponibilidade (em quantidade e qualidade) de recursos naturais para as atuais e futuras gerações, o que implica obrigatoriamente em educação dos sujeitos para a sensibilização às questões ambientais, como água, solo, fauna, flora, produção e consumo de alimentos. Para tanto, se faz necessário que as dinâmicas educativas incorporem em suas estruturas curriculares e nas práxis pedagógicas dos educadores, ações de Educação Ambiental, o que inclui princípios e práticas de Agroecologia.

A Agroecologia apresenta-se como um novo paradigma na produção do conhecimento, envolvendo tanto o conhecimento científico como o saber popular. Ela visa desenvolver as bases teóricas, metodológicas e científicas para o desenvolvimento de uma agricultura sustentável, essa agricultura estruturada em processos produtivos que são gerados pela integração do conhecimento científico e do conhecimento local, levando em consideração as bases ecológicas que regem os processos reprodutivos dos diferentes elementos do ecossistema (GLIESSEMAN, 2009).

A Agroecologia surge da multidisciplinaridade científica, sendo assim uma ciência integradora de saberes, conhecimentos e experiências de distintos atores sociais, dando suporte à emergência de um novo paradigma de desenvolvimento 
rural, onde a educação possui papel fundamental (CAPORAL; COSTABEBER, 2004). Como matriz disciplinar a Agroecologia se encontra no campo que Morin (1999, p. 33) identifica como sendo do pensar complexo, em que complexus significa o que é tecido junto, assim "o pensamento complexo é o pensamento que se esforça para unir, não na confusão, mas operando diferenciações".

Logo, a Agroecologia não se enquadra no paradigma convencional, cartesiano e reducionista, conhecido como o paradigma da simplificação (disjunção ou redução), pois, como orienta Morin (1999) esse não consegue reconhecer a existência do problema da complexidade. Trata-se de assentir que as relações do homem com outros homens e destes com os outros seres vivos e com o meio ambiente, requer um novo enfoque paradigmático, capaz de unir os saberes populares com os conhecimentos criados por diferentes disciplinas científicas, de modo que possamos dar conta da totalidade dos problemas e não do tratamento isolado de suas partes. A agroecologia proporciona o conhecimento e a metodologia necessários para desenvolver uma agricultura que é ambientalmente consistente, produtiva e economicamente viável (GLIESSMAN, 2009).

Busca restabelecer a harmonia das relações entre o homem e seu espaço natural, fazendo com que o impacto das atividades agrícolas no ambiente seja mínimo e que sejam ampliados os benefícios da agricultura para além do espaço rural, superando o mito deste como mero produtor de alimentos e sim como espaço e ambiente de vida (GUIMARÃES et al., 2015). No entanto, a educação agrícola ainda está alicerçada nos conhecimentos tecnológicos atrelados a lógica comercial/industrial (uso de insumos agroquímicos, sementes geneticamente modificadas, etc.), acarretando em problemas como contaminação do meio ambiente, extinção de fauna e flora (mais recentemente, as abelhas ${ }^{3}$ ) e êxodo rural.

De outro lado, o ensino da Agroecologia vem ocupando gradativamente espaços nas universidades, trazendo aos educadores o desafio da compreensão e do ensino-aprendizagem de uma ciência ainda em construção. Especificamente no que se refere aos professores das Ciências Agrárias observam-se lacunas acerca da formação e atuação docente, ainda impregnada dos pressupostos da difusão tecnológica em suas práxis pedagógicas pautadas pelo uso de insumos químicos, experimentos e análises quantitativas como instrumentos de validação de pesquisas agrícolas (CAPORAL; COSTABEBER, 2004).

Fonseca (2004) corrobora com esta reflexão quando alerta que as teorias pedagógicas têm se revestido de racionalidade técnica e neutralidade científica para ocultar o caráter político da educação, reduzindo assim os problemas educacionais à questões metodológicas. Neste contexto faz-se mister a e construção de uma "nova" cultura de trabalho e produção, esta preocupada com a autonomia dos sujeitos, meio ambiente e compromisso com as gerações futuras colocando na pauta do ensino para o rural, a necessidade de novos processos educativos.

Buscando contribuir com reflexões acerca deste cenário, foi idealizada uma pesquisa com estudantes dos cursos de Agronomia, Zootecnia, Medicina Veterinária e Pós-Graduação em Extensão Rural da Universidade Federal de Santa Maria/Brasil. Objetivou-se evidenciar a percepção dos sujeitos acadêmicos no que

\footnotetext{
${ }^{3}$ O US Fish and Wildlife Service (FWS) - o Ibama dos EUA anunciou que as abelhas entraram para a lista de espécies ameaçadas de extinção. A hipótese do FWS é que a razão principal tenha sido a inclusão de espécies de plantas e animais invasores, que desequilibraram a fauna local. Desde 2006, apicultores do mundo inteiro têm reclamado que as populações do inseto caíram. De 2012 para 2013, 31\% das abelhas dos EUA tinham desaparecido; na Europa, naquele período, o número chegou a $53 \%$, e no Brasil, a quase $30 \% \%$. Ver mais em http://exame.abril.com.br/tecnologia/abelhas-entram-para-a-lista-de-especies-emextincao/.
} 
se refere às contribuições do uso do audiovisual no ensino-aprendizagem da Agroecologia, buscando compreender o uso do vídeo como objeto educacional mediador da Ciência Agroeocológica, bem como conhecer a receptividade dos acadêmicos ao uso das tecnologias digitais em sala de aula.

\section{O EMPÍRICO DA PESQUISA: DA CAPTAÇÃO DE IMAGENS A PRODUĈ̃̃ DE VÍDEOS EDUCATIVOS COMO OBJETO EDUCACIONAL MEDIADOR DA AGROECOLOGIA}

Objetos educacionais são recursos em diversos formatos e linguagens, que tem por objetivo mediar e qualificar o processo de ensino-aprendizagem. Uma de suas principais características é a "reusabilidade", que diz respeito à capacidade de reutilização dos materiais produzidos, em diferentes contextos de aprendizagem, nas mais diversas áreas do conhecimento (BISOL, 2010).

Objetivando contribuir para o ensino-aprendizagem da Agroeocologia nos cursos citados acima (objetos da pesquisa) foram produzidos dois audiovisuais que sistematizam experiências de transição agroecológica, mais precisamente na produção de "leite a pasto" com utilização do Pastoreio Racional Voisin (PRV) e uso de homeopatia, em propriedades rurais familiares de Santa Maria - RS, experiências estas em curso desde 2011 com um conjunto de resultados já sistematizados que permitiram a produção dos audiovisuais.

A elaboração dos vídeos, como objeto educacional foi realizada a partir de imagens captadas durante "Dias de Campo" realizados pela Emater e Universidade Federal de Santa Maria (UFSM), através do Departamento de Educação Agrícola e Extensão Rural (DEAER).

Evidenciam-se no vídeo troca de experiências entre produtores como forma de fortalecer as práticas agroecológicas, sempre com o intuito de compartilhamento das práticas apreendidas, bem como a valorização do conhecimento dos agricultores, isto registrado por meio de depoimentos dos sujeitos $\mathrm{e}$ acompanhamento de seus sistemas produtivos.

As experiências em foco enfatizam transição agroeocológica na produção de leite de base orgânica, a partir do uso do $\mathrm{PRV}^{4}$. Este consiste em um sistema de produção que resgata a intimidade do produtor e seus animais, a partir da vivência e observação dos animais e crescimento das pastagens, permitindo um aumento na produtividade sem degradar os recursos naturais, proporcionando assim um aumento progressivo da fertilidade do solo, entre outros benefícios (MACHADO, 2003).

Os vídeos apresentam o PRV como tecnologia capaz de promover a transição agroeocológica enfatizando elementos que a potencializam como tal. Destacam-se nas imagens captadas elementos como relação homem/meio ambiente, bem-estar animal e depoimentos dos agricultores com suas trajetórias e pareceres.

Com relação a variável homem/meio ambiente, as cenas registradas destacam a valorização do campo nativo, preservação de áreas com matas nativas e os piquetes para pastejo dos animais incorporados a estas áreas, evidenciando

\footnotetext{
4 Neste modelo alternativo de produção busca-se alcançar o equilíbrio dinâmico ou ecológico do ecossistema, que segundo Marangon et al. (2004), caracteriza-se pela estabilidade da função e estrutura do ecossistema, onde mesmo havendo perturbações constantes em pequena escala, os organismos resistem às tensões e fatores limitantes do ambiente, sendo esta potencialidade diretamente ligada à capacidade de resiliência desses organismos no ambiente. Daí a utilização desta tecnologia como propulsora da transição Agroecológica.
} 
uma lógica conservacionista da produção, onde ao invés de desmatar, incorporamse as áreas de pastagens ao sistema ecológico já existente.

As falas dos produtores confirmam o compromisso destes com o meio ambiente e a qualidade dos alimentos produzidos (leite), destaca um dos produtores:

\begin{abstract}
O químico é complicado! A gente entende que quanto mais natural melhor... o que mais prejudica é a saúde, se tem que trabalhar com produto de qualidade, o melhor é produzir o alimento orgânico... tem que trabalhar dentro de uma lógica. A homeopatia é o que gente acredita (PRODUTOR A, fala no minuto 2:40 do vídeo).
\end{abstract}

Quanto ao Bem-Estar Animal, as cenas do vídeo expõem situações de mansidão dos animais, possibilitando facilidade de manejo, disponibilidade de água em todos os piquetes e sombreamento em abundância e ainda respeito aos animais que são identificados por nome e não por números.

No que se refere tecnicamente ao PRV, as orientações são demonstradas pelos proprietários, dentro da lógica metodológica "De produtor para produtor", onde o técnico é o mediador e os produtores protagonistas do Dia de Campo.

Por fim, com relação aos elementos em destaque no vídeo, tem-se depoimento dos agricultores quanto a sua trajetória e pareceres a respeito do PRV. As falas remetem à percepção dos agricultores com relação aos benefícios do sistema de piqueteamento e uso homeopatia e ainda troca de vivências das dificuldades encontradas, como por exemplo, a falta de sucessão familiar como se destaca nos relatos a seguir:

Tudo funciona bem deste jeito... a propriedade poderia estar ainda melhor, mas a gente já tem idade 6.0 não é fácil, os filhos não querem seguir, se tivesse alguém pra assumir a gente tinha mais vontade de fazer... (PRODUTOR B fala no minuto 4:15 do vídeo).

Na verdade, parece ser caro, mas no fim das contas diminui os custos e as perdas, por que não tem descartes de leite. Não tem o problema da mastite, já se resolveu, faz oito meses que não apresenta problemas nenhum na produção (PRODUTOR A fala no minuto $3: 35$ do vídeo).

De forma dinâmica as falas e imagens de organização das propriedades, com registro da interação entre os animais e seu agroecossistema foram sendo registradas pelas câmaras e dispositivos móveis (celulares), onde todo o processo como questionamentos e particularidades descritas pelos produtores foram registrados.

Cabe ressaltar que os procedimentos de captação do material, através de gravações de áudio e vídeo durante as visitas que subsidiam o conteúdo para a produção dos vídeos, foram coletados baseando-se em experiências já consolidadas com produtores que apresentam resultados positivos, possibilitando registros de experiência já com alguns anos de atividade e a outra no seu início de implantação.

A partir destes idealizou-se a produção de dois vídeos com oito minutos de duração cada, expondo a importância da Agroecologia como matriz produtiva para a sustentabilidade e como esta pode ser incorporada aos sistemas produtivos de criação animal, mais especificamente na produção leiteira e ainda a condição dos agricultores como protagonistas das dinâmicas de construção do conhecimento. 
A produção deste material audiovisual constituiu a base da pesquisa possibilitando a identificação da percepção ${ }^{5}$ de acadêmicos acerca das potencialidades do uso do vídeo na promoção e visibilidade da Agroecologia. Percepções estas identificadas e analisadas por meio da aplicação de questionários semiestruturados junto aos educandos de Graduação em Agronomia, Zootecnia, Medicina Veterinária e Pós-Graduação em Extensão Rural da UFSM, mais especificamente nas disciplinas de Extensão Rural, Desenvolvimento Rural, Extensão e Comunicação Rural e ainda Comunicação e Mediação Social.

Estes cursos e disciplinas foram escolhidos por abordarem a temática da sustentabilidade e Agroecologia, possibilitando ao pesquisador espaços de discussões.

O trabalho apresenta abordagem qualitativa, caracterizada por Spink e Menegon (1999), como aquela que aponta para a complexidade dos fenômenos sociais. O método utilizado foi o estudo de caso, este compreendido como uma investigação empírica que permite o estudo de um fenômeno contemporâneo dentro de seu contexto da vida real (YING, 2005).

Com relação aos instrumentos de pesquisa, foram utilizadas entrevistas semiestruturadas. Esta, como técnica de pesquisa visa obter informações de interesse a uma investigação, onde o pesquisador formula perguntas orientadoras com um objetivo definido, frente a frente com o respondente e dentro de uma interação social. Os escolhidos são participantes ativos da problemática em estudo, contribuindo desta forma para a apreensão das questões, fatos e informações relevantes para o pesquisador (GIL, 1999).

Assim foram aplicados questionários a 30 discentes. As questões norteadoras das entrevistas foram divididas em dois aspectos: a) Percepção dos entrevistados com relação às informações passadas pelo audiovisual; b) Percepção dos entrevistados com relação às metodologias digitais utilizadas nas Ciências Agrárias.

Tais percepções identificadas a partir da aplicação de questionário, logo após a visualização do vídeo. Estes eram oferecidos aos sujeitos em caráter de contribuição à pesquisa, esta desenvolvida em três ambientes de ensinoaprendizagem: 1) Em sala de aula; 2) No Ambiente Moodle das Disciplinas em questão; 3) Em página criada na Rede Social Facebook.

Os resultados encontrados foram divididos em: a) Percepção do audiovisual como mediador do ensino-aprendizagem da Agroecologia; b) Percepção dos sujeitos com relação às metodologias digitais utilizadas nas Ciências Agrárias; c) Contribuições do uso do vídeo na compreensão do conhecimento em Agroecologia e Desenvolvimento Rural Sustentável.

\footnotetext{
5 O trabalho toma como referência o sentido de Percepção dado por Marilena Chaui que se refere a esta como uma experiência ou ainda uma sensação dotada de sentidos que se relacionam com a história de vida dos sujeitos, fazendo parte do mundo destes e suas vivências. Por esta razão, segundo a autora, a percepção envolve toda a personalidade do sujeito, sua história pessoal, afetividade, desejos e paixões, onde o mundo é percebido qualitativamente, afetivamente e valorativamente (CHAUI, 1999).
} 


\subsection{PERCEPÇÃO DOS SUJEITOS COM RELAÇÃO AO AUDIOVISUAL COMO MEDIADOR DO ENSINO APRENDIZAGEM DA AGROECOLOGIA}

As questões indicadas no questionário, que permitiram a percepção dos sujeitos com relação ao ensino-aprendizagem da Agroecologia foram divididas em: excelente; muito boa; boa; regular e ruim, devendo ser elencadas como opção única.

Verificou-se que a maioria dos entrevistados avalia o vídeo como um método de aprendizagem, positivo. Nesse universo $50 \%$ dos entrevistados apontaram para o vídeo como Muito Bom, 29,16\% como Excelente e 8,33\% como Bom.

As avaliações acenam para o uso do vídeo como um método capaz de contribuir para o ensino-aprendizado das ciências agroecológicas, indo de encontro as afirmações de Moran (2000) que sugere que aprendemos melhor quando vivenciamos e sentimos, o que permite estabelecer laços e sentidos entre o objeto de estudo e o pesquisador/estudante.

Moran (2000) e Gomes (2009) ainda identificam o vídeo educacional, como uma opção de recurso tecnológico adequado para o uso na educação, desde que sejam observados aspectos como planejamento do que deve ser contemplado e ainda a disponibilidade de recursos de mídia nos espaços educativos.

Em contrapartida, 4,16\% dos entrevistados avaliam o uso do vídeo como método de aprendizagem Regular, sendo que $8,33 \%$ não acreditam no audiovisual como ferramenta didático-educativa, trazendo a necessidade de reflexões acerca da preparação dos estudantes para o uso das TER.

Quando questionados com relação às motivações proporcionados pelo uso do vídeo, as opções de respostas acenavam para o vídeo como: incentivo para melhora do aprendizado; como nova forma de apreender; como promoção de autonomia do aprendizado; motivação para a temática e por fim a opção não me incentivou. Aqui as opções de resposta eram múltiplas.

Neste quesito as respostas apontam que $45 \%$ acreditam no vídeo com nova forma de aprender, $29,16 \%$ acha que melhora o seu aprendizado, $25 \%$ percebe o vídeo com uma motivação para a temática, 8,33\% não se sentiu motivado ao assistir o vídeo e por fim $4,16 \%$ apontou para este como facilitador para a autonomia do aprendizado.

A partir das respostas, devem-se considerar as potencialidades apresentadas pelo uso do vídeo na construção do conhecimento, apontando para a criação de uma educação inovadora, construída a partir da problematização do tema segundo o expectador, corroborando com o que Lèvy (2000) exemplifica quando diz que mesmo sentado em frente a uma televisão o usuário decodifica, interpreta e participa organizando sua compreensão de muitas maneiras, sempre diferentes das do seu vizinho.

Quando $45 \%$ acreditam no vídeo como uma nova forma de aprender e cerca de $30 \%$ como algo que melhora o aprendizado, ressalta-se o que Pires (2010) identifica como fenômeno de comunicação, onde se misturam os papéis de educador e educando, resultando daí um processo de diálogo, o que por sua vez facilita a construção do conhecimento.

No que se refere a motivação para a temática, apontado por $25 \%$ dos entrevistados, identifica-se o vídeo como mediador do conhecimento a partir da possibilidade de diálogos com a realidade. Esta dinâmica pode ser compreendida como interatividade entre os sujeitos, que sempre em maior ou menor grau, participa como receptor ativo, codificando tudo o que recebe (LÈVY, 2000).

No entanto há que se considerar que apenas $4 \%$ dos entrevistados apontaram o vídeo com facilitador para autonomia de aprendizado, sugerindo este 
como método alternativo complementar ao convencional, ancorado em mídias escritas e exposições orais, mas que não o substitui.

Por fim, completando a sistematização das percepções acerca do uso do vídeo, os alunos entrevistados foram questionados sobre a contribuição deste para a compreensão do conhecimento em Agroecologia e Desenvolvimento Rural Sustentável.

Na percepção da maioria dos entrevistados, o vídeo contribuiu para estudos de Agroecologia e compreensão do Desenvolvimento Rural Sustentável, elencando potencialidades de diálogos com a realidade o que facilita e estimula a compreensão dessas temáticas, como descreve o entrevistado estudante de graduação, quando diz que "é uma maneira de mostrar a realidade de diferentes locais, auxiliando na situação de ida ao campo, mas por meio de vídeo, o que faz com que se torne mais sociável o aprendizado".

Aqui, justificam-se os propósitos de Paulo Freire (1992) que aponta para a conexão do sujeito com a realidade que estuda, como fundamentais para o estimulo ao aprendizado contextualizando que este só acontece quando há diálogo entre estes, neste caso facilitado pelo uso do vídeo que aproxima a realidade vivenciada pelos produtores do ambiente de sala de aula.

Outra percepção em destaque nas entrevistas avalia o vídeo com importante para abordagem de elementos técnicos não contemplados nas disciplinas das grades curriculares dos cursos, enfatizando o PRV, a homeopatia e ainda Agroecologia, uma vez que tais conteúdos, não seriam discutidos em sala de aula de outra forma que não através do vídeo, que ao trazer experiências regionais acabou por promover curiosidades acerca do tema. Como cita o entrevistado estudante de graduação "o vídeo trouxe importantes elementos sobre PRV e homeopatia que estão ligados as questões de saúde pública, mas que não são trabalhados em sala de aula".

Ballen e Silveira (2015) contribuem para esta reflexão quando acusam as ciências agrárias como ainda muito vinculada às bases epistemológicas da modernização da agricultura da década de 70 , caracterizada pela desconexão do homem ao meio ambiente quando de suas práticas agronômicas. Neste sentido os autores apontam para a necessidade de novas bases epistêmicas e referenciais teóricos para discussões e ações para a sustentabilidade.

Os entrevistados ressaltam, sob esta ótica, que o vídeo, por meio da abordagem empírica (realidade dos produtores de Santa Maria - RS) fortalece a Agroecologia como ciência e ainda como estratégia de geração e renda. Abaixo a percepção de um estudante de pós-graduação

\footnotetext{
O vídeo auxilia a compreender e buscar alternativas com bases agroecológicas para se trabalhar no campo o que fortalece a construção da Agroecologia, tanto como campo científico, quanto múltiplas alternativas sustentáveis e de geração de renda, uma renda mais justa, racional e limpa (social, cultural, econômica e equitativa).
}

Outras percepções destacadas entre os entrevistados apontam o vídeo como auxílio e praticidade para fixação do conteúdo, identificando este como facilitador da aprendizagem por meio do visual, que auxilia na memorização. É o que Machado (2005) expõe como um sistema híbrido que opera diversos códigos de comunicação, utilizando elementos do cinema, teatro, literatura, rádio e computação gráfica, que somados a situações de realidade, podem potencializar a recriação de 
sentidos e aprendizado. O entrevistado, aluno de pós-graduação, corrobora para esta percepção quando diz que:

Ao meu ver, o vídeo cumpre totalmente o papel de contribuir para a compreensão do conhecimento em Agroecologia e Desenvolvimento Rural Sustentável. O vídeo faz isso, por exemplo, ao expor na prática metodologias de construção de conhecimento, caso do método Produtor a produtor (onde, através do diálogo, realizam trocas de conhecimento e o técnico estabelece um papel de mediação). Outro ponto importante que o trabalho apresenta é a noção do que representa em olhar a propriedade como um todo, o vídeo mostra que ali mora uma família de pessoas com uma idade mais avançada, e, portanto, faz-se necessário um trabalho com menor penosidades... O vídeo se torna, desta forma, uma boa ferramenta para discutir vários conceitos teóricos relacionados à Agroecologia e várias práticas relacionadas ao Desenvolvimento Rural Sustentável.

Completando a percepção dos entrevistados quanto às contribuições do vídeo para a compreensão dos conhecimentos em Agroecologia e Desenvolvimento Rural Sustentável, outro entrevistado, estudante de pós-graduação, aponta a seguinte observação:

\begin{abstract}
Através deste tipo de ferramenta sempre há contribuições (quando o trabalho é bem realizado, claro), o que pode acontecer é a dificuldade de o vídeo abordar os temas em um espaço curto. Então busca-se resolver de duas formas: ou um vídeo longo e cansativo, ou curto e carecendo de maiores esclarecimentos. Acho que, para técnicos e pessoal da área, o vídeo cumpre o papel de informar e contribuir, mas, para leigos, carece de outros elementos.
\end{abstract}

Aqui se evidenciam lacunas no uso do vídeo como material didático pedagógico, pois de fato a abordagem teórica torna-se um desafio para a elaboração dos materiais uma vez que, do ponto de vista pedagógico, vídeos longos podem tornar-se cansativos, e de outro lado, quando simplistas e curtos, correm o risco de não contribuir para o aprendizado, mesmo estimulando o espectador.

Finalizando esta seção, as respostas elencadas entre os entrevistados apontam, de forma geral, para a importância do vídeo como instrumento didático educativo uma vez que estas possibilitam comunicação, facilitando diálogos e compreensões, a partir de novas dinâmicas de construção do conhecimento, onde o uso das tecnologias contribui para reelaboração de "velhas percepções", tendo o audiovisual como mediador deste processo (PIRES, 2010).

As percepções elencadas a partir das questões norteadoras possibilitam reflexões e geram novas possibilidades quando discutidas em sala de aula. As repostas apontam para aceitação do uso do vídeo como material pedagógico complementar do ensino-aprendizagem, não substituindo o professor, mas colaborando com a memorização e ainda subjetivação do conteúdo. Além disso, no caso específico das Ciências Agroecológicas o vídeo permitiu aproximação das disciplinas á realidade regional, favorecendo diálogos universidade/comunidade. 


\title{
4.2. PERCEPÇÕES DOS SUJEITOS COM RELAÇÃO ÀS METODOLOGIAS DIGITAIS UTILIZADAS NAS CIÊNCIAS AGRÁRIAS
}

Esta seção foi idealizada objetivando tecer reflexões acerca do uso de metodologias digitais no ensino das Ciências Agrárias. Os vídeos e os questionários foram disponibilizados em diferentes ambientes: a) Na sala de aula; b) No Ambiente Virtual das Disciplinas (Moodle) e c) Rede Social Facebook, a partir do uso da ferramenta Criação de Grupo Público, no caso, intitulado "Pesquisa: O uso do Vídeo no fomento à Agroecologia".

Para tanto foram elaboradas duas questões norteadoras, uma com relação ao uso das TIC como enriquecedoras do aprendizado e outra referente a procura de vídeos como complementares aos conteúdos trabalhados em aula, onde foram questionados os sites mais buscados.

Com relação ao uso das Tecnologias Digitais de Informação e Comunicação como enriquecedoras do aprendizado evidenciou-se a importância de mudança na forma de propagação da informação, com a criação de ambientes virtuais e do uso de recursos audiovisuais que facilitem o ensino aprendizado, tornando-o mais interativo e dinâmico.

Neste contexto, Pires (2010) salienta que se evidencia no vídeo um fenômeno de comunicação, que se dissemina de forma processual no tecido social, resultando num processo de troca e de diálogo. Abaixo, o relato de um dos alunos de graduação entrevistado, referindo-se às tecnologias como facilitadoras do ensino aprendizado:

\begin{abstract}
Acredito que o vídeo ajuda muito. Cada pessoa desenvolve sua maneira de ler e compreender o mundo, isto não ocorre de forma diferente durante o aprendizado. Desta forma, acredito que quanto maior o número de recursos disponíveis, mais rico é o processo de aprender. Somos diferentes na forma de pensar e aprender, então se uma pessoa aprende muito mais vendo e outra aprende muito mais ouvindo, nada mais justo que possamos ter ferramentas que dialoguem com cada uma destas pessoas.
\end{abstract}

A percepção do aluno demonstra a possibilidade de diversificação dos métodos de ensino-aprendizagem, que em um contexto de subjetividade, enriquece as formas de "apreender", uma vez que o sujeito, a partir de suas individualidades, possui diferentes caminhos e formas para elaborar seu conhecimento. Além disso, deve-se destacar que novas práticas e ambientes de "depósito" de conteúdos possibilita a utilização destes em diferentes momentos e ainda mantê-los arquivado, para utilização quando necessário, reinventado e ampliando seu significado e sentidos a cada momento, como sugere o aluno de graduação entrevistado:

Penso que através desse meio, temos a oportunidade de visualizar na prática, atividades que não estão muitas vezes ao nosso alcance no dia-a-dia. E ainda, têm a facilidade de uso por não necessitarem de deslocamentos, que no caso de aulas práticas são um empecilho, assim como, podem ser utilizadas a qualquer momento do dia, em qualquer dia da semana e ainda ser arquivadas, como se a gente pudesse ir a campo qualquer dia e hora. 
A pesquisa permite ainda tecer algumas considerações quanto à eficiência do Moodle para esta atividade, onde considerando as configurações da Plataforma utilizada pela UFSM, a possibilidade da hospedagem de vídeos tem restrições quanto ao tamanho do arquivo, demonstrando lacunas em sua eficiência como repositório de materiais audiovisuais, que para sua incorporação ainda carece de link com outros endereços da internet, como Youtube e outros sites, dificultando a visualização do audiovisual em foco que só foi possível a partir de link com a plataforma de vídeos "Youtube".

Como o material produzido não pode ser disponibilizado diretamente no Moodle (para tanto criou-se o link) idealizou-se então um grupo na Rede Social Facebook que possibilitou a hospedagem do vídeo, disponibilização do arquivo do questionário em Word e ainda descrição do trabalho de pesquisa, com seus objetivos e propósitos, convidando os estudantes a contribuir. $\mathrm{O}$ endereço do grupo criado no Facebook foi "linkado" no Ambiente Virtual das disciplinas no Moodle direcionando o estudante diretamente para o vídeo,

Além das questões norteadoras do trabalho, descrita nos objetivos esta sistemática metodológica permitiu também percepções acerca da receptividade dos sujeitos entrevistados a diferentes ambientes de ensino aprendizagem, desde a sala de aula, passando pelo Ambiente Virtual convencionado como oficial da UFSM (Moodle), até o uso das Redes Sociais, no caso, o Facebook.

Quanto ao Moodle evidencia-se sua colaboração como repositório de materiais, mas com limite de dados a serem incorporados, assim o vídeo foi apenas "linkado" no ambiente e não depositado no mesmo, fazendo com que este tivesse que ser anexado a outro ambiente virtual, onde então a criação da Página do Facebook possibilitou cobrir esta lacuna. Importante salientar que as percepções acerca da facilidade e preferências de uso das mídias digitais constituiu um dos achados da pesquisa, apontando para a necessidade de trabalhos que avaliem tendências e construam possibilidades de acesso educativo aos mais diferentes ambientes de conexão.

A outra questão orientadora das percepções referente a procura de vídeos para aprofundar conteúdos trabalhados em aula, bem como os sites procurados apontou, em $100 \%$ dos entrevistados, que a busca por conteúdos disponíveis em vídeo é uma tendência em tempos de globalização, onde a sociedade está conectada em redes, como afirma Castells (2000).

Os endereços mais utilizados para busca de materiais em vídeos são o Youtube e sites específicos das temáticas, que segundo relatam os entrevistados, tanto de graduação, como de pós-graduação, são em número significativo e, em sua maioria, disponibilizam vídeos como material didático, em complemento a artigos científicos e boletins técnicos.

No que se refere pontualmente à temática da Agroecologia, os alunos apontam páginas de Organizações Não Governamentais, Grupos de Estudos disponíveis no Facebook e ainda Páginas e Blogs de Grupos de trabalho universitários.

Percebe-se, a partir das respostas, que as redes sociais possibilitam fazer a interlocução entre conteúdo e sujeito, sendo que a plataforma de vídeos Youtube é o maior e mais popular site de conteúdo audiovisual gratuito disponível na internet.

Moran (2000) afirma que há uma excelente forma de aproveitar o potencial que a internet oferece. Para tanto, deve-se equilibrar a rapidez e a quantidade de informações disponíveis com a análise e a reflexão acerca dos conteúdos apresentados. Os sujeitos podem e devem ser incluídos neste processo, sendo imbuídos a pesquisar, avaliar os conteúdos, considerar questões importantes e julgar as fontes. 
As percepções descritas apontam para um potencial transformador nas formas de ensinar e apreender, onde a busca por novas alternativas passam pelas Tecnologias Educacionais em Rede (TER). No entanto muito deve ser trilhado no sentido da apropriação de educadores e educandos às tecnologias digitais.

No caso específico das Ciências Agrárias evidencia-se ainda certa desconfiança da validade do vídeo como instrumento de aprendizagem e mesmo linguagem acadêmico científica trazendo à tona a necessidade de discussões acerca das práxis pedagógicas dos discentes, que ainda permanecem atrelados a noções tradicionais de ensino aprendizagem.

\section{CONSIDERAÇÕES FINAIS: SIGNIFICAÇÕES ACERCA DO USO DO VÍDEO NO ENSINO-APRENDIZAGEM DA AGROECOLOGIA}

Estamos reaprendendo a conhecer, a comunicar-nos, a ensinar e a aprender, a integrar o humano e o tecnológico. Entretanto, é necessário que se perceba que uma mudança qualitativa no processo de ensino-aprendizagem só acontece quando se consegue integrar, dentro de uma visão inovadora todas as metodologias educacionais: as audiovisuais, as textuais, as orais, musicais, lúdicas e corporais (MORAN, 2000).

O vídeo é uma importante ferramenta educacional, constituindo recurso tecnológico adequado para uso na educação, desde que seja utilizado de maneira adequada, com o devido planejamento e combinado com outras mídias e recursos didáticos.

Autores como Moran (2000) e Gomes (2009) defendem que uso do vídeo educacional deve ser acompanhado de proposta pedagógica consciente das exigências de uma educação transformadora que priorize a criatividade, a pesquisa e a formação para a cidadania. Moran ainda complementa afirmando que o vídeo educacional não deve simplesmente reproduzir conteúdo, mas deve favorecer a produção de novas formas de interação entre o conteúdo, os alunos e o ambiente natural.

No caso da pesquisa, a produção do audiovisual como uma forma de abordagem e estímulo à Agroecologia e o Desenvolvimento Rural Sustentável, permitiu a visibilidade de novos Sistemas Produtivos, permitindo reflexões acerca de elementos importantes como a busca por autonomia dos agricultores, a importância da agricultura familiar no contexto da sustentabilidade e o compromisso com a produção de alimentos de qualidade.

O desenvolvimento desta temática por meio do vídeo tornou possível a ampliação e propagação de conhecimentos construídos a partir da realidade dos sujeitos, por meio da mediação proporcionada pelas tecnologias digitais, bem como ampliou as formas de expressão científica, que na atualidade, exigem esforços acadêmicos que vão para além da escrita, incorporando a estas, imagens, sons, sentidos e novas significações.

Observando demandas e lacunas referentes a espaços acadêmicos que abordem a temática, ainda em segundo plano nas estruturas curriculares dos cursos de Ciências Agrárias da UFSM, a elaboração do vídeo possibilitou sensibilização para o tema da Agroecologia, que por sua vez pode despertar interesse à formação e capacitação dos sujeitos, isto em caráter de interatividade, facilitando a elaboração de ideias, pareceres e visões de mundo, o que os permite avaliar o vídeo, na condição de um método de ensino aprendizagem, como colaborador na formação de sujeitos independentes e autônomos na elaboração de seu conhecimento.

Moran (2000) afirma que a produção audiovisual possui dimensões modernas e lúdicas. Isso explica porque os jovens adoram fazer vídeos, o que 
atualmente é muito fácil. Equipamentos como smartphones e tablets tornam a ação de filmar bastante fácil e acessível sendo ainda a importação dos vídeos para o computador e para diferentes sites, ação simples e rápida.

Neste contexto faz-se necessário incentivar mais a produção de vídeo para utilização como recurso de ensino-aprendizagem, pois estes possibilitam a maior compreensão e aprofundamento de um conteúdo específico. Ao trabalhar efetivamente na produção, gravação e publicação do vídeo, os sujeitos se envolvem mais com o objeto do estudo, o que corrobora para uma compreensão mais profunda acerca do mesmo e para o sucesso do processo de aprendizado.

Através da utilização de recursos audiovisuais, os ouvintes se sentem capazes de visualizar uma experiência, mais facilmente de que se buscasse a informação através de leitura, facilitando a aproximação do assunto para explorar as informações e tecnologias as quais teve acesso.

Por isso o vídeo elaborado partiu da realidade local (município de Santa Maria) mostrando que há espaço para novas abordagens tecnológicas e que para isso faz-se urgente a formação de novos profissionais, alicerçados em bases epistemológicas condizentes com a busca de autonomia dos agricultores e a harmonização dos sistemas produtivos com os recursos naturais, possibilitando assim mudanças de pensamento e convicção para superar os desafios da ruptura com o modelo convencional.

Os resultados das percepções dos alunos entrevistados apontam para a necessidade urgente de revisão das práticas docentes e mesmo das bases epistemológicas onde se ancoram as Ciências Agrárias, uma vez que o paradigma da sustentabilidade requer novos posicionamentos acadêmicos para a formação de profissionais capazes de contribuir com o Desenvolvimento do País, este alicerçado na equidade social, respeito ao saberes tradicionais e equilíbrio dos ecossistemas.

\section{REFERÊNCIAS}

ANDRADE, B. O.; SANTOS, M. S. T. Extensão rural e cibercultura: o facebook como ferramenta de promoção da política nacional de assistência técnica e extensão rural. Extensão Rural, Santa Maria, v. 22, n. 3, p. 29-47, jul./set. 2015. Disponível em: <https://periodicos.ufsm.br/extensaorural/article/view/10014/pdf>. Acesso em: 15 set. 2017.

BISOL, C. A. Ciberespaço: terceiro elemento na relação ensinante/ aprendente. In: VALENTINI, C. B.; SOARES, E. M. S. (Org.) Aprendizagem em ambientes virtuais: compartilhando ideias e construindo cenários. Caxias do Sul: EDUCS, 2010. p. 21-32.

BALEN, T. A.; SILVEIRA, P. R. C. Velhas e novas interrogações sobre a formação tecnológica para a agricultura familiar. In: GUIMARÃES, G. M.; BALEM, T. A.; SILVEIRA, R. C.; ZIMMERMANN, S. A. (org) O rural contemporâneo em debate: temas emergentes e novas institucionalidades. Ijuí: Editora Unijuí, 2015.

BELLONI, M. L. Educação a distância. 2 ed. São Paulo: Editora Autores Associados, 1999.

CAPORAL, F. R.; COSTABEBER, J. A. Agroecologia e extensão rural: contribuições para a promoção do desenvolvimento rural sustentável. Brasília: MDA/SAF/DATER - IICA, 2004. 
CASTELLS, M. A Sociedade em rede: A era da informação, economia, sociedade e cultura. 2 ed. v. 1. São Paulo: Paz e terra, 1999.

A sociedade em rede. São Paulo: Paz e Terra, 2000.

A galáxia da internet: reflexões sobre a internet, os negócios e a sociedade. Rio de Janeiro, Editora Paz e Terra, 2003.

CHAUI, M. Convite à filosofia. São Paulo: Ática, 1999.

DUBOIS, P. Cinema, vídeo. Godard. São Paulo: Cosac Naify, 2004.

FONSECA, M.; OLIVEIRA, J. F.; TOSCHI, M. S. Escolas gerenciadas: planos de desenvolvimento e projetos político pedagógicos em debate. Goiânia: UCG, 2004.

FREIRE, P. Extensão ou comunicação? São Paulo: Paz e Terra. (1992).

FREIRE, P. Pedagogia do oprimido. 17ª edição. Rio de Janeiro: Paz e Terra, 1987.

GIL, A. C. Entrevista. In: Métodos e técnicas de pesquisa social. 5. ed. São Paulo: Atlas, 1999. Cap. 11, p. 117-127.

GLIESSEMAN, S. R. Agroecologia: processos ecológicos em agricultura sustentável. Porto Alegre: Editora UFRGS, 2009.

GOMES, L. F. Vídeos didáticos: uma proposta de critérios para análise. Disponível em:<http://www.unioeste.br/prppg/mestrados/letras/revistas/travessias/ed 004/artigo s/educacao/pd fs/V\%CDDEOS\%20DID\%C1TICOS.pdf >. Acesso em: 2 nov. 2009.

GUIMARÃES, G. M.; BALEM, T. A.; SILVEIRA, R. C.; ZIMMERMANN, S. A. (org) 0 rural contemporâneo em debate: temas emergentes e novas institucionalidades. ljuí: Editora Unijuí, 2015.

KENSKI, V. M. Tecnologias e ensino presencial e a distância. Campinas, SP: Papirus, 2003.

LÉVY, P. A inteligência coletiva: por uma antropologia do ciberespaço. 4. ed. São Paulo: Loyola, 2000.

MACHADO, A. Pré-cinemas \& pós-cinemas. São Paulo: Papiros, 2003.

MORAES, M. C.; TORRES, S. L. Sentir e pensar: fundamentos e práticas para reencantar a educação. Petrópolis/RJ: Vozes, 2004.

MORAN, J. M. et al. Novas tecnologias e mediação pedagógica. Campinas: Papirus, 6 ed., 2000.

MORIN, E. Os sete saberes necessários á prática educativa. São Paulo: Cortez, 1999. 
PIRES, E. G. A experiência audiovisual nos espaços educativos: possíveis interseções entre educação e comunicação, Educação e Pesquisa, São Paulo, v. 36, n. 1, p. 281-295, jan./Abr. 2010.

SPINK, M. J. P.; MENEGON, V. N. A pesquisa como prática discursiva: superando os horrores metodológicos. In: SPINK, M. J. P (Org.). Práticas discursivas e produção de sentidos no cotidiano: aproximações teóricas e metodológicas. São Paulo: Cortez, 1999.

YIN, R. K. Estudo de caso: planejamento e métodos. 3. ed. Porto Alegre: Bookman, 2005. 